\title{
Hilbert Transform based Fuzzy Expert System for Diagnosing and Classifying Power Quality Disturbances
}

\author{
P. Kalyana Sundaram \\ Assistant Professor \\ Department of Electrical Engineering \\ Annamalai University
}

\author{
R. Neela \\ Professor \\ Department of Electrical Engineering \\ Annamalai University
}

\begin{abstract}
This paper presents a new technique for diagnosis and classification of power quality disturbances. The proposed method applies Hilbert transform to analyze the distorted voltage waveforms and then extract their features. The distorted voltage waveforms are generated by Matlab simulink on the test system. The extracted input features such as standard deviation and variances are given as inputs to the fuzzy-expert system that uses some rules to classify the Power Quality disturbances. Fuzzy classifier has been constructed to classify both the single and combined form power quality disturbances. The results clearly show that the proposed method has the ability to diagnosize and classify Power Quality problems. The results obtained by the proposed method are validated by comparing them against Hilbert Transform based neural classifiers.
\end{abstract}

\section{General Terms}

$x(t)$ - Real signal

$x_{H T}(t)-$ Hilbert transform signal

$\lambda$ - Shifting operator

$(-j \operatorname{sgn}(\Omega))$ - Shifting the negative frequency of $x(t)$

$A(t)$ - Envelop signal of $x(t)$

$\theta(t)$ - Instantaneous phase signal of $x(t)$

$\tilde{A}$ - Envelop mean value of the signal

$V_{a r}(t)$ - Variances of the envelop signal

$S_{t d}(t)-$ Standard deviation of the signal

\section{Keywords}

Power quality, Power quality disturbances, Hilbert transforms, Fuzzy-expert system.

\section{INTRODUCTION}

Power quality disturbances and their consequences have become an important problem in electric power system. Power quality problems generally occur due to the variation in the electric voltage or current such as sag, swell, interruption, harmonics, sag with harmonics, swell with harmonics, flicker and notches. Hence it is necessary to detect and classify those disturbances. An adaptive linear neural network based power quality analyzer for the estimation of electric power quality has been applied and the disturbances were classified in [1]. Windowed FFT which is the time windowed version of discrete Fourier transform has been applied for power quality analysis to classify a variety of disturbances in [2].
Wavelet transform along with multi-resolution signal decomposition for the classification of power quality disturbances has been applied in [3]. The on-line power quality disturbances classification using wavelet multiresolution signal decomposition and Pattern recognition technique has been discussed in [4]. Wavelet multi-resolution technique along with neuro-fuzzy classifier for PQ disturbance detection has been explained in [5]. Classification of power quality disturbances using a combination of ambiguity plane concept and Fisher discriminant kernel along with feed forward neural classifier has been presented in [6] .Hybrid technique of the discrete STFT along with wavelet transform for the analysis of power quality disturbances has been demonstrated in [7]. Application of s-transform for power quality analysis has been discussed in [8].

S-transform based neural network for the detection and classification of PQ disturbance signal has been implemented in [9]. The power quality disturbance data compressed using the combined form of splines along with wavelet transform and then S-transform based pattern classifiers were implemented to classify the PQ disturbances in [10]. Multi resolution S-transform based fuzzy classifier has been presented in [11] for power quality disturbances classification. A two dimensional representation for analyzing various types of power quality events using DWT decomposition technique has been implemented in [12]. An S-transform based modular neural network has been presented in [13] and this combines the frequency resolution characteristics of $S$ transform with the pattern recognizing ability of a neural network. Wavelet multi resolution analysis along with Self-Organizing Learning Array (SOLAR) for the power disturbances characterization has been presented in [14].

Support vector machine (SVM) based electric power quality disturbance classification has been illustrated in [15]. The classification of the power quality disturbances based on Stransform and Probabilistic neural network has been discussed in [16]. Probabilistic neural network method based on optimal feature selection for power quality event classification has been illustrated in [17]. A kalman filter based fuzzy expert system for the characterization of power quality disturbances has been illustrated in [18]. Classifications of various non stationary power quality disturbances based on EMD along with Hilbert transform and neural network has been elaborated in [19]. Classification of both the single and combined nature of power quality disturbances using signal spare decomposition (SSD) has been illustrated in [20]. A Hilbert transform, fuzzy expert system based power quality analyzer in which features are extracted through Hilbert transform and disturbances are classified using fuzzy expert system is presented in this paper. 


\section{PROPOSED TECHNIQUE}

The proposed technique has two stages. They are
1) Feature extraction stage and
2) Classification stage.

In the feature extraction stage, Hilbert transform is used for extracting the input features. The classification stage consists of fuzzy rule based expert system. Disturbance waveforms were generated using Matlab simulink on test system.

\subsection{Feature Extraction Stage}

The Hilbert Transform is used to generate an analytical signal obtained by convolving the real signal with the function as shown below.

$$
\begin{aligned}
x_{H T}(t) & =x(t)\left(\frac{1}{\pi t}\right) \\
x_{H T}(t) & =\frac{1}{\pi} \int_{-\infty}^{\infty} x\left(\frac{\lambda}{(t-\lambda}\right) d \lambda \\
x_{H T}(t) & =-j \operatorname{sgn}(\Omega) X(\Omega)
\end{aligned}
$$

The output of the Hilbert transform is $90^{\circ}$ phase shift of the original signal $x(t)$, a complex signal. It is defined as

$$
\begin{aligned}
& x_{C}(t)=x(t)+j x_{H}(t) \\
& x_{C}(t)=A(t) e^{j \theta(t)}
\end{aligned}
$$

The analytical signal has the information about amplitude as well phase of the signal. The amplitude, phase and envelop mean value are given by

$$
\begin{aligned}
& A(t)=\sqrt{x^{2}(t)+x_{H T}^{2}(t)} \\
& \theta(t)=\tan ^{-1}\left(\frac{x_{H T}(t)}{x(t)}\right) \\
& \tilde{A}=T^{-1} \int_{0}^{T} A(t) d t
\end{aligned}
$$

The variances of the envelop signal is the first input to fuzzy system. It is directly computed from the envelop mean value as follows

$$
V_{a r}(t)=\left(x_{H T}(t)-\tilde{\AA}\right)^{2}
$$

The standard deviation is the second input to fuzzy system. It is obtained from the following relationship as given below

$$
S_{t d}(t)=\sqrt{V_{a r}(t)}
$$

\subsection{Fuzzy Expert System}

Fuzzy system provides a simple way to arrive at a definite conclusion based upon ambiguous inputs. The mamdani type of fuzzy inference system used to perform the classification of the PQ events. It has two inputs and generates one output based on 25 rules. The first input to the system is the value of standard deviation. The input is divided into five trapezoidal membership functions namely VSTD (very small standard deviation), SSTD (small standard deviation), NSTD (normal standard deviation), LSTD (large standard deviation), and VLSTD (very large standard deviation). The second input to the system is the value of variances. It is broken into five triangular membership functions namely VV (very small variance), SV (small variance), $\mathrm{NV}$ (normal variance), $\mathrm{LV}$ (large variance), and VLV (very large variance). The fuzzy expert system is shown in figure 1

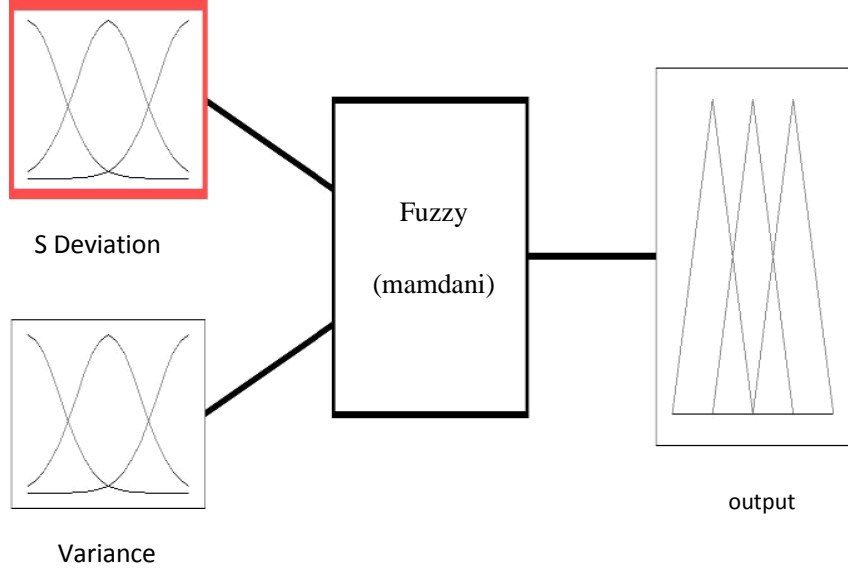

Figure 1.Fuzzy expert system

The brief rule sets of fuzzy expert system are given below:

1) If (Standard deviation is VSTD) and (Variance is $\mathrm{VV}$ ) then (output is INTERRUPTION).

2) If (Standard deviation is VSTD) and (Variance is $\mathrm{SV})$ then (output is INTERRUPTION).

3) If (Standard deviation is VSTD) and (Variance is $\mathrm{NV}$ ) then (output is INTERRUPTION).

4) If (Standard deviation is VSTD) and (Variance is LV) then (output is SWELL).

5) If (Standard deviation is VSTD) and (Variance is VLV) then (output is NORMAL).

6) If (Standard deviation is SSTD) and (Variance is $\mathrm{VV}$ ) then (output is INTERRUPTION).

7) If (Standard deviation is SSTD) and (Variance is $\mathrm{SV}$ ) then (output is INTERRUPTION).

8) If (Standard deviation is SSTD) and (Variance is $\mathrm{NV}$ ) then (output is SAG).

9) If (Standard deviation is SSTD) and (Variance is LV) then (output is NORMAL).

10) If (Standard deviation is SSTD) and (Variance is VLV) then (output is SWELL).

11) If (Standard deviation is NSTD) and (Variance is $\mathrm{VV}$ ) then (output is INTERRUPTION).

12) If (Standard deviation is NSTD) and (Variance is $\mathrm{SV}$ ) then (output is SAG).

13) If (Standard deviation is NSTD) and (Variance is $\mathrm{NV}$ ) then (output is NORMAL).

14) If (Standard deviation is NSTD) and (Variance is LV) then (output is SWELL).

15) If (Standard deviation is NSTD) and (Variance is VLV) then (output is HARMONICS).

16) If (Standard deviation is LSTD) and (Variance is $\mathrm{VV}$ ) then (output is SAG).

17) If (Standard deviation is LSTD) and (Variance is $\mathrm{SV}$ ) then (output is NORMAL).

18) If (Standard deviation is LSTD) and (Variance is $\mathrm{NV}$ ) then (output is SWELL).

19) If (Standard deviation is LSTD) and (Variance is VLV) then (output is SAG WITH HARMONICS). 
20) If (Standard deviation is LSTD) and (Variance is VLV) then (output is SWELL WITH HARMONICS).

21) If (Standard deviation is VLSTD) and (Variance is VV) then (output is NORMAL).

22) If (Standard deviation is VLSTD) and (Variance is $\mathrm{SV}$ ) then (output is SWELL).

23) If (Standard deviation is VLSTD) and (Variance is NV) then (output is HARMONICS).

24) If (Standard deviation is VLSTD) and (Variance is VLV) then (output is FLICKER).

25) If (Standard deviation is VLSTD) and (Variance is VLV) then (output is NOTCH).

The rule viewer of the fuzzy expert system is shown in figure 2 .

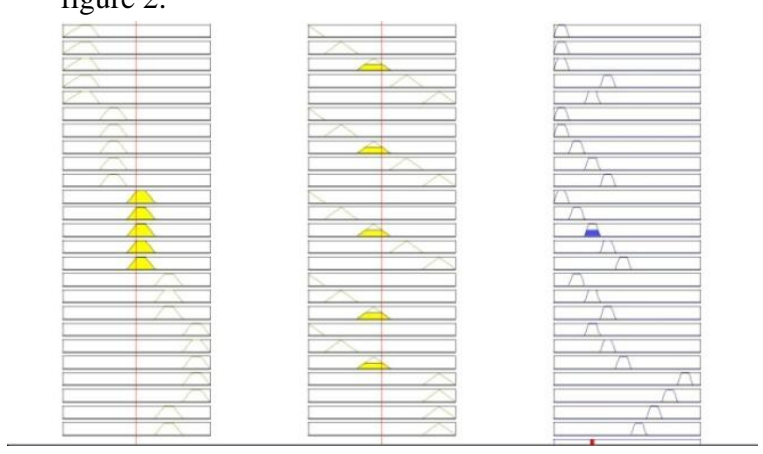

Figure 2.Rule viewer of fuzzy expert system

\section{CLASSIFICATION STAGE USING FUZZY EXPERT SYSTEM}

The proposed fuzzy expert system has been used to analyze and classify the eight types of power quality disturbances. The extracted input features through the Hilbert Transform are applied as inputs to the fuzzy expert system in order to classify the disturbances. Fuzzy logic with the rule based expert system has emerged the classification tool for PQ events. The rules of this technique are based on modeling human experience and expertise.

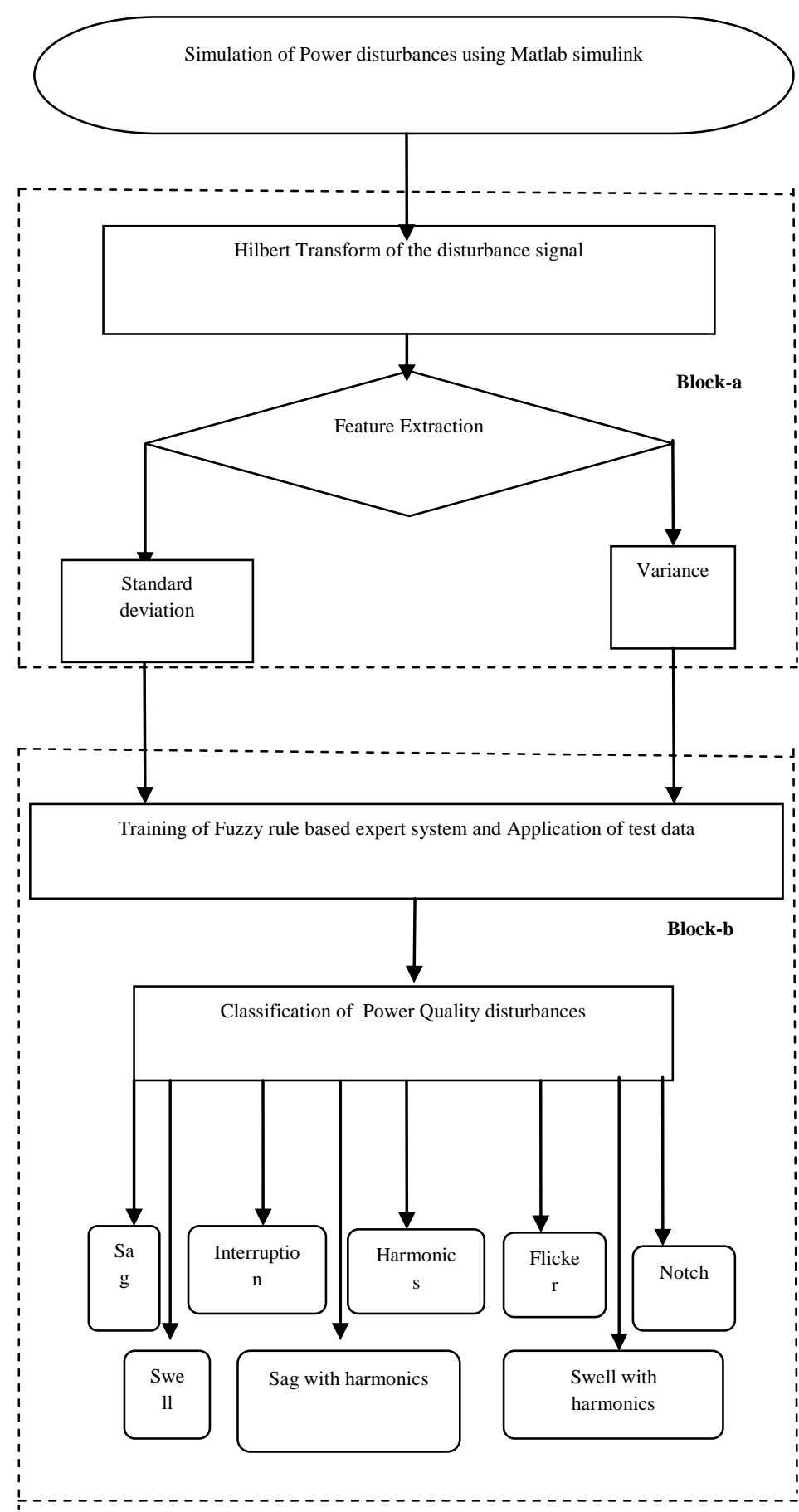

Figure 3. Flowchart for the Classification of Power Quality disturbances

\section{SIMULATION AND TEST RESULTS}

Testing data were generated using Matlab simulink on the test system model for various classes of disturbances and the signals closer to real situation can be simulated. The nine types of different power quality disturbances, namely pure sine (normal), sag, swell, outage, harmonics, sag with harmonic, swell with harmonic, notch and flicker were considered. The single line diagram for the test system and the Matlab simulation block diagram are shown in figure 5 and figure 6 . 


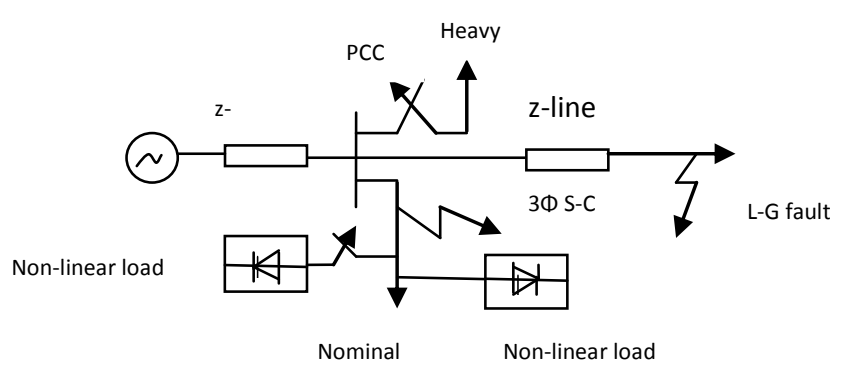

Figure 4.Single line diagram of test system model

These input signals are applied to the fuzzy expert system to get accurate classification of disturbances. The PQ disturbance signals generated using the Matlab based parametric equations. The following case studies are presented to highlight the suitability of the application of the proposed method.

Pure sine wave is the normal voltage signal at the frequency $50 \mathrm{~Hz}$ and its waveform is as shown in the figure 5(a).The Hilbert transform of the pure sine wave signal are shown in the figures $5(b)$.

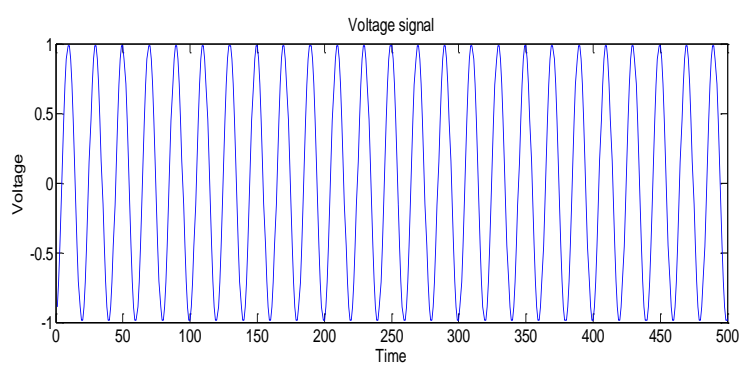

Figure 5(a)

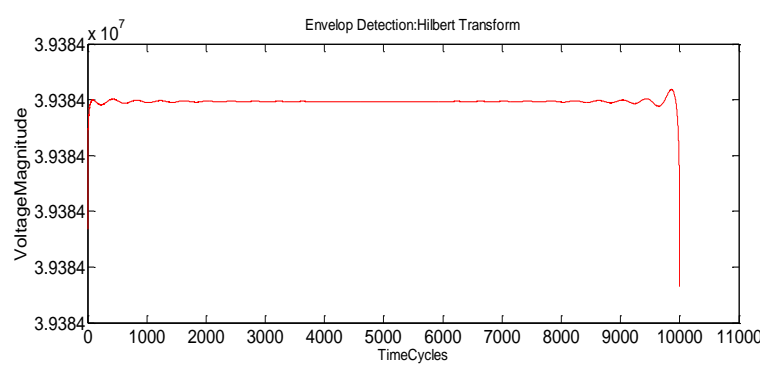

Figure 5(b)

The single form of power quality disturbances are given below

Voltage sag (or) voltage dip causes a decrease of system voltage. The duration of the sag disturbance is 0.4 to 0.8 cycles in $1 \mathrm{~min}$. The voltage dip is generated by the occurrence of a single line to ground fault. It is shown in the figure 6(a) and Hilbert transform of the voltage dip signal are shown in figure $6(b)$.

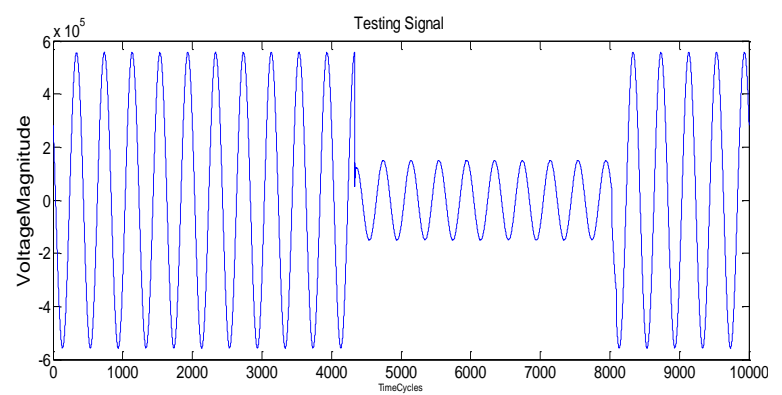

\section{Figure 6(a)}

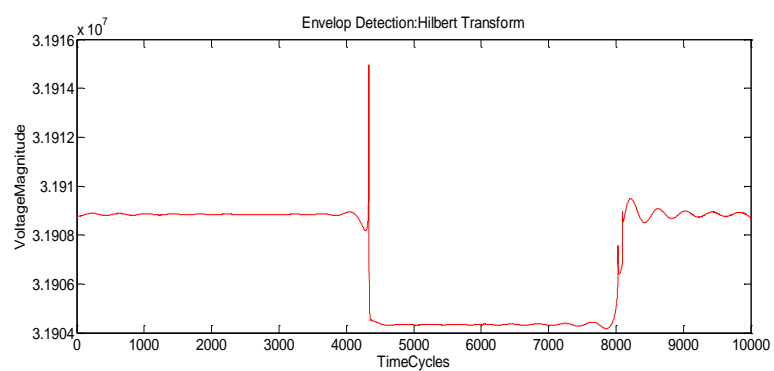

Figure 6(b)

Voltage swell causes the rise of system voltage. The duration of the swell disturbance is 0.4 to 0.8 cycles in $1 \mathrm{~min}$. The voltage swell is generated by disconnecting the heavy load for 10 cycles and its waveform is shown in the figure 7(a). The Hilbert transform of the voltage swell event is shown in figure 7(b).

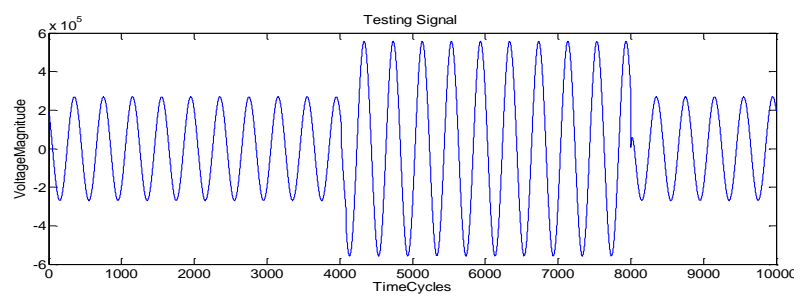

Figure 7(a)

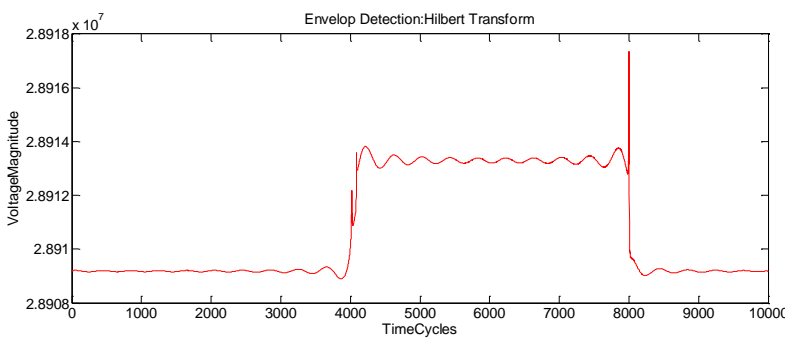

Figure 7(b)

Voltage surge causes the sudden rise of the voltage in the short duration of time. The duration of the surge disturbance is 0.2 to 0.22 cycles in $1 \mathrm{~min}$. The voltage surge is generated by disconnecting the heavy load for one quarter cycle and its waveform is shown in the figure 8(a).The Hilbert transform of the voltage surge event is shown in the figure $8(\mathrm{~b})$.

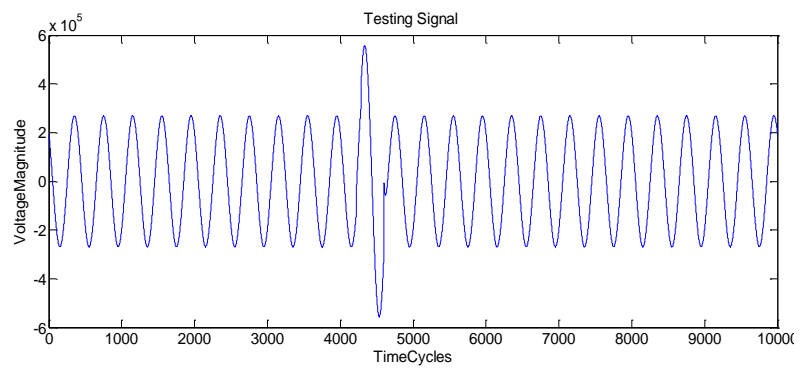

Figure 8(a) 


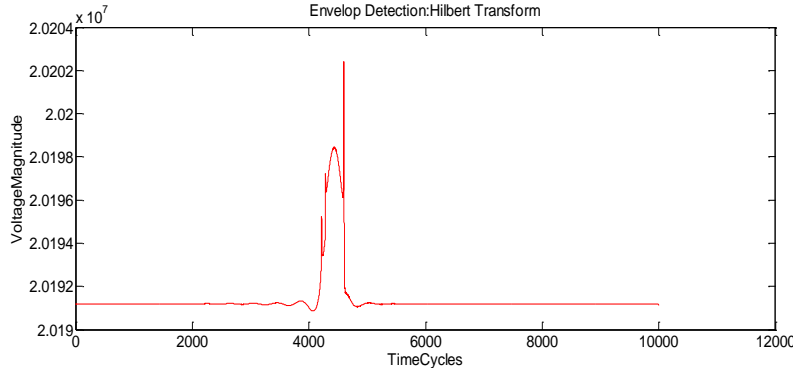

Figure 8(b)

Voltage interruption causes the loss of the voltage on the system. The duration of the voltage interruption is 0.4 to 0.8 cycles. The voltage interruption is generated by three phase short circuit fault and its waveform is shown in the figure 9(a). The Hilbert transform of the voltage interruption signal is shown in the figure $9(\mathrm{~b})$.

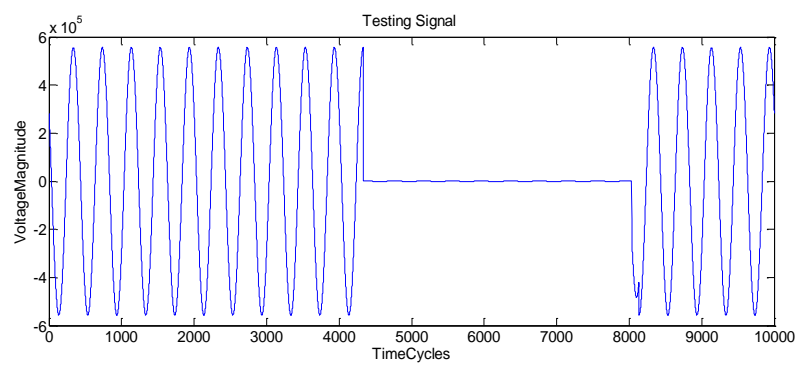

Figure 9(a)

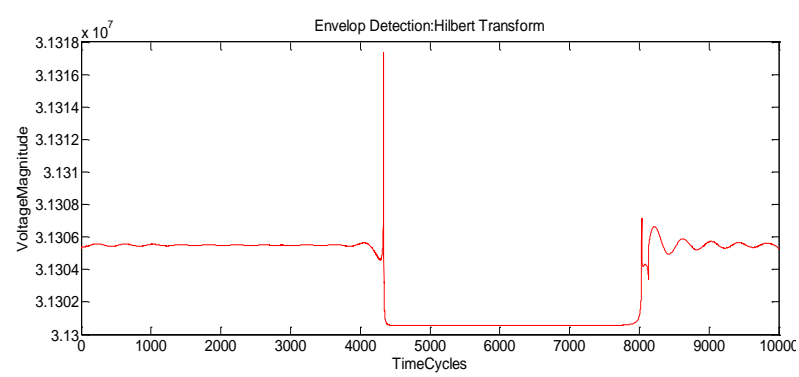

Figure 9(b)

Harmonics are generated by the connection of non linear load to the system. The distortion of the voltage waveform is shown in the figure 10(a). The Hilbert transform of the harmonics signal is shown in the figures 10(b).

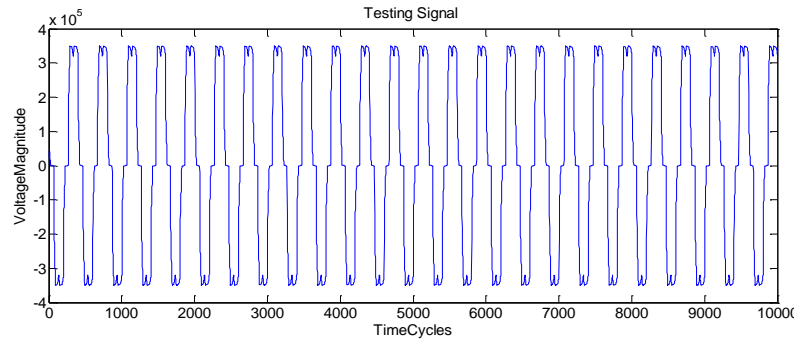

Figure 10(a)

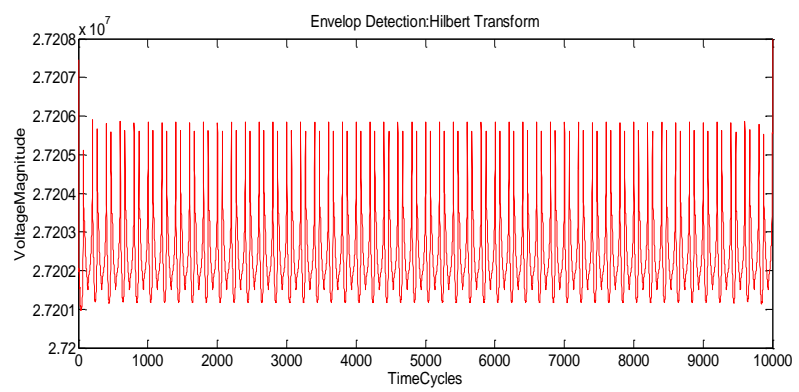

Figure 10(b)

Flicker is caused by the continuous and rapid variation of the system load. The flicker disturbances are generated by disconnecting the heavy load in the continuous nature at regular interval and the waveform of the flicker is shown in the figure 11(a). The Hilbert transform of the flicker disturbances is shown in the figures 11(b).
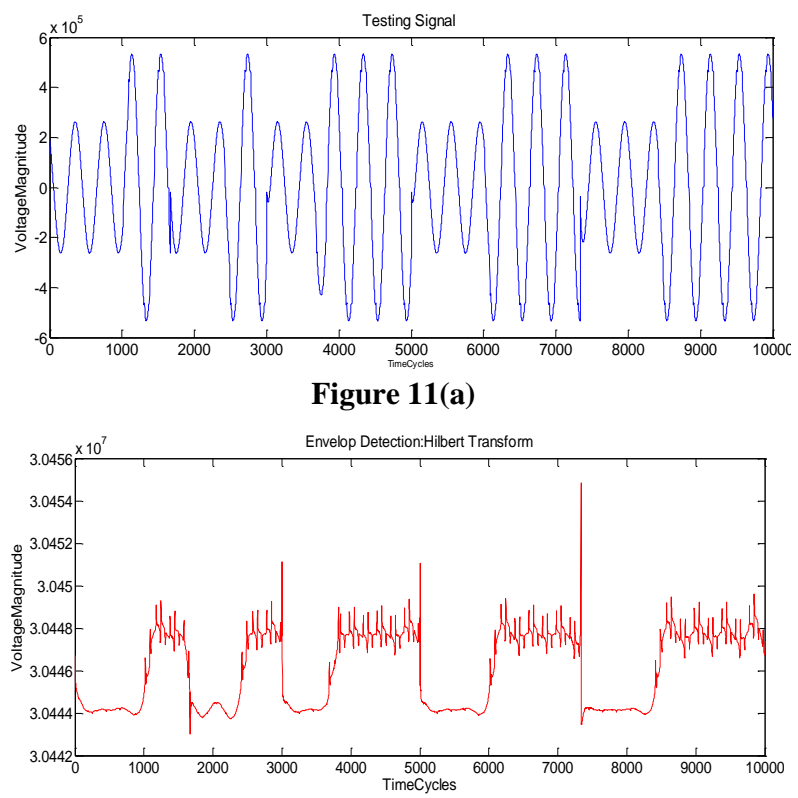

Figure 11(b)

Notch is a disturbance of the nominal power voltage waveform lasting for less than half a cycle. The disturbance is initially of opposite polarity and hence it is to be subtracted from the waveform as shown in the figure 12(a). The Hilbert transform signal of notch is shown in figure 12(b). 


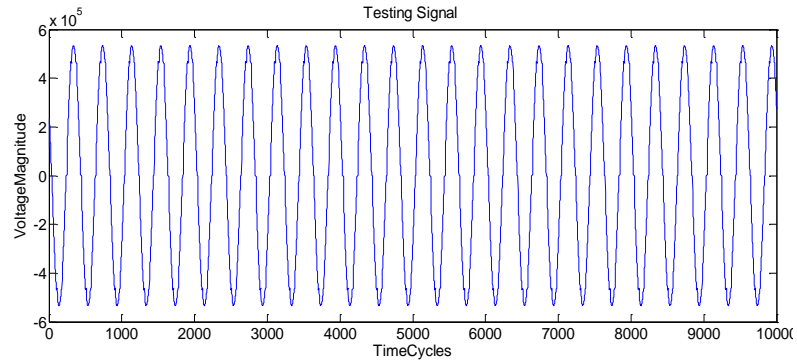

Figure 12(a)

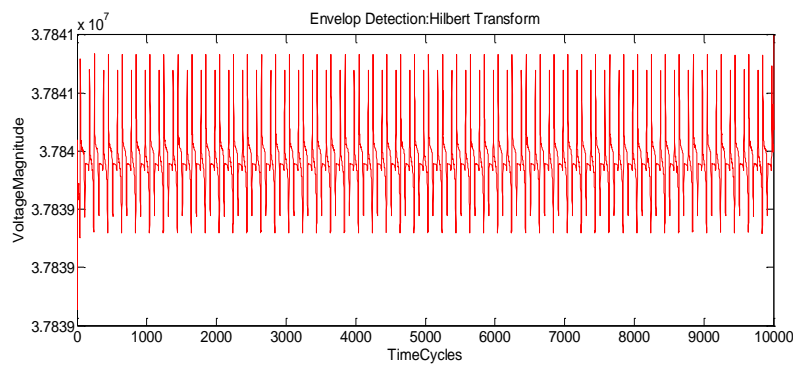

Figure 12(b)

The combined form of the multiple power quality disturbances are given below

Sag with harmonics is caused by the presence of a nonlinear load and a voltage dip in the system for a duration of 0.5 to 0.8 cycles .The waveform contain harmonic distortion with sag event as shown in the figure 13(a). The Hilbert transform of this disturbance is shown in the figure 13(b).

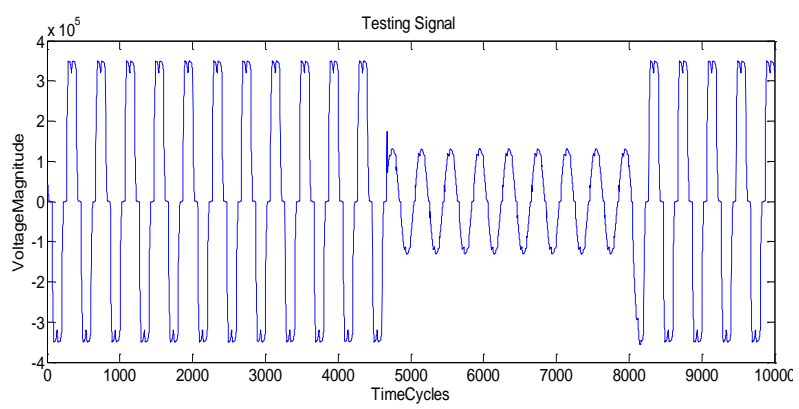

Figure 13(a)

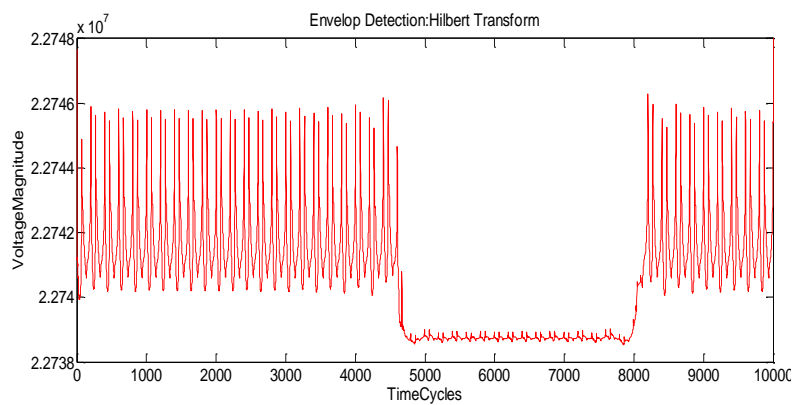

Figure 13(b)

Swell with harmonics is caused by the presence of nonlinear load and a voltage swell for the duration of 0.4 to 0.8 cycles. The waveform contains harmonic distortion with swell event as shown in the figure 14(a). The Hilbert transform of the swell with.harmonics is shown in figure 14(b).

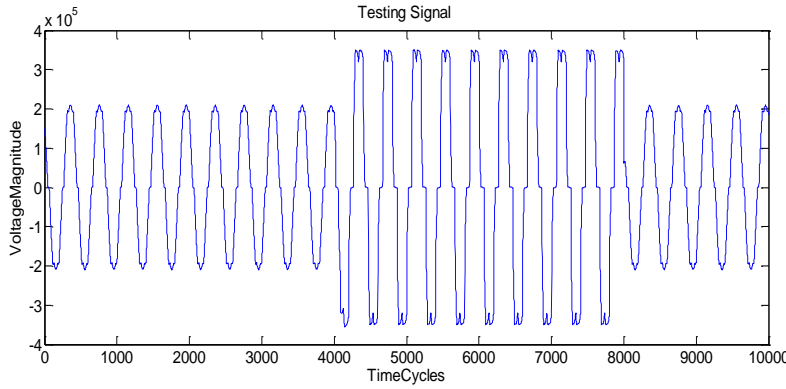

Figure 14(a)

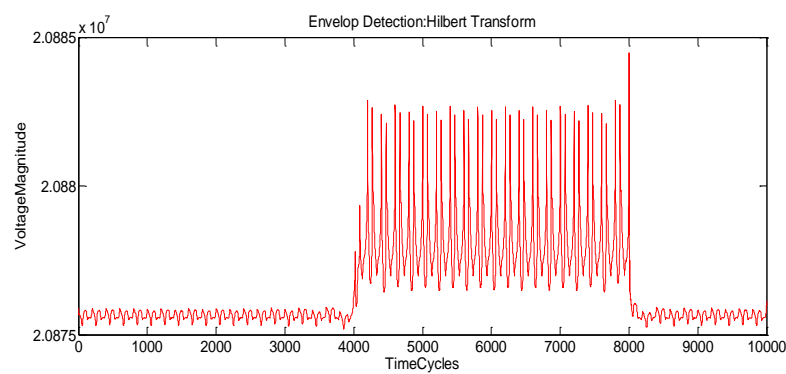

Figure 14(b)

Extraction of three input features such as mean, peak value and standard deviation from the single and combined form of power quality disturbances are given below. They are

- The input features extraction from the pure sine wave is given in figure 15 (a).
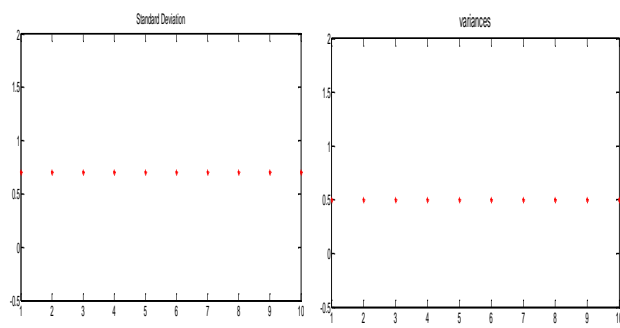

- The input features extraction from the single form of power quality disturbances; 15(b) Sag, 15(c) Swell, 15(d) Surge, 15(d) Interruption, 15(e) Harmonics, 15(f) Flicker and 15(g) Notch

$15(b)$

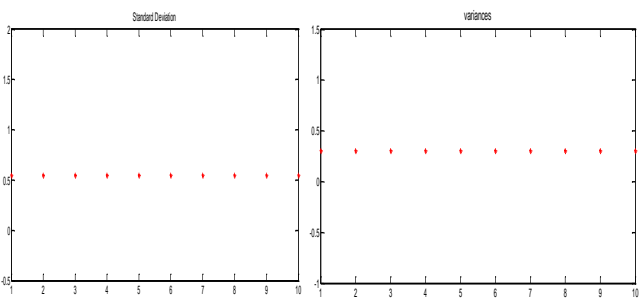

15(c)

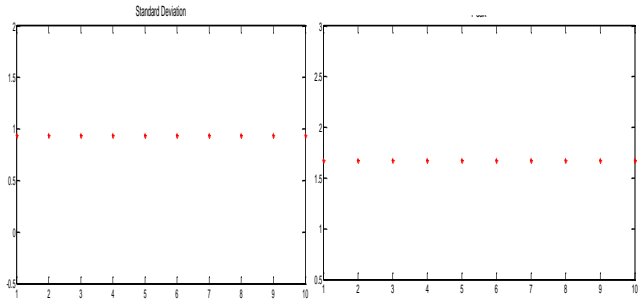


15(d)
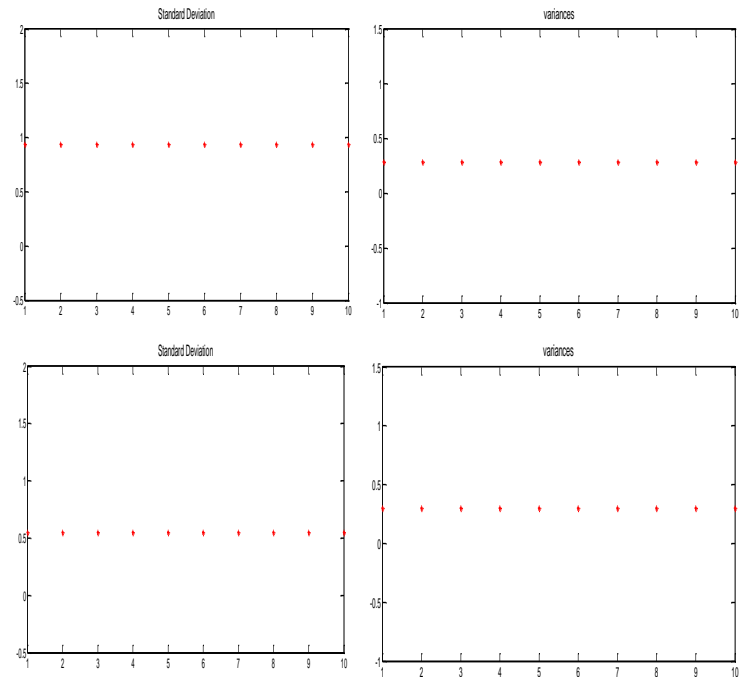

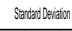

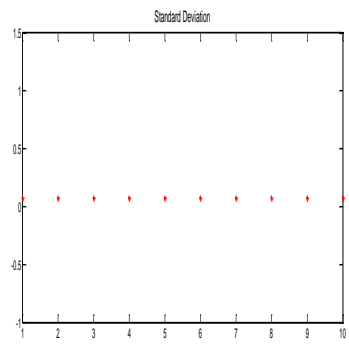

Saturalorian

15(g)
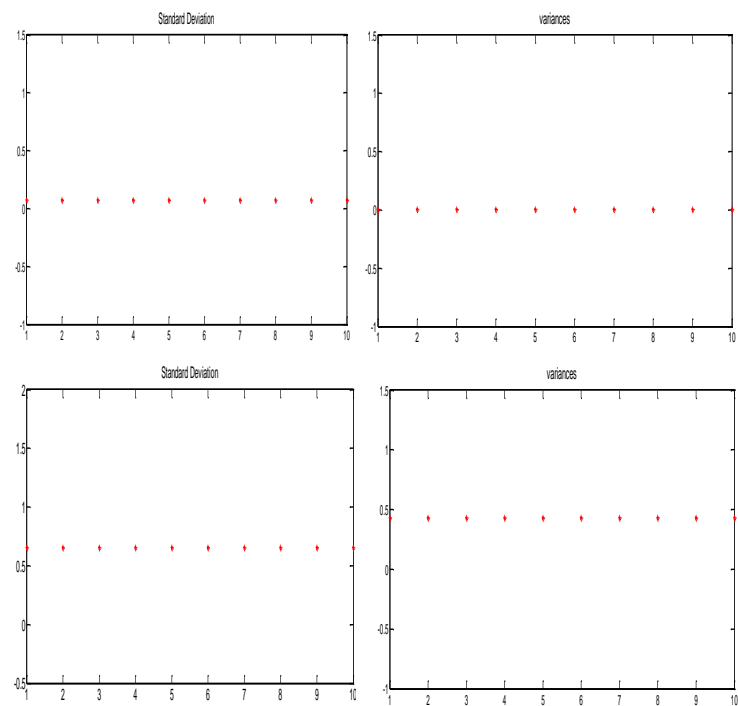

घaranes

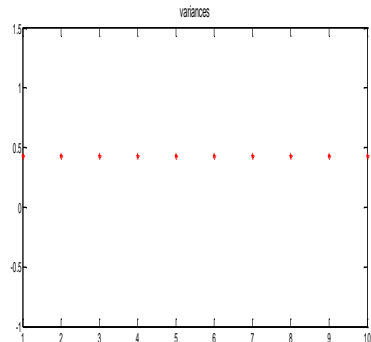

- The input features extraction from the combined form of power quality disturbances; 15(h) Sag with harmonics and 15(i) Swell with harmonics

$15(h)$
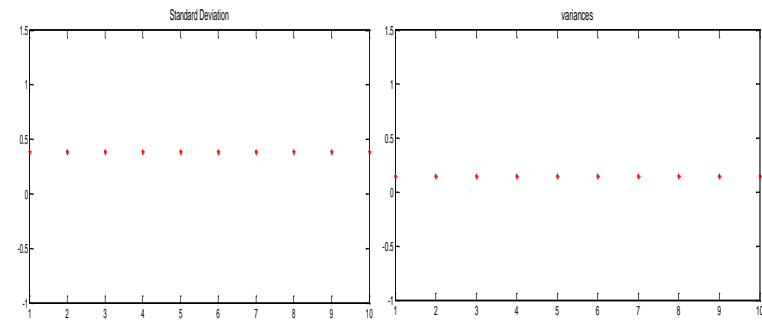

varanes
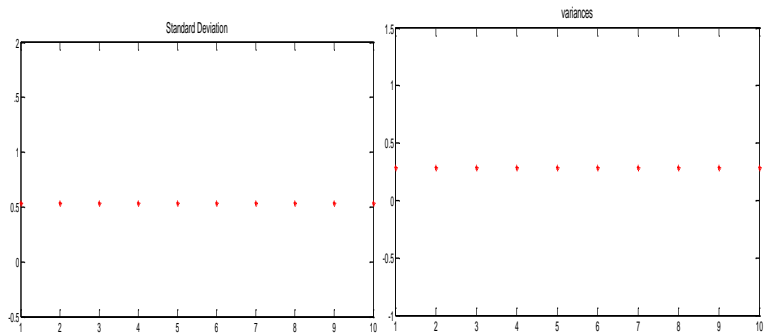

Table 1 Comparison of classification accuracy

\begin{tabular}{|c|l|c|c|c|}
\hline Sno & \multicolumn{1}{|c|}{$\begin{array}{c}\text { Power } \\
\text { Quality } \\
\text { Disturbances }\end{array}$} & features & $\begin{array}{c}\text { Input } \\
\text { transfor } \\
\mathrm{m} \\
\text { based } \\
\text { MLP } \\
\text { network }\end{array}$ & $\begin{array}{c}\text { Hilbert } \\
\text { transform } \\
\text { based } \\
\text { fuzzy expert } \\
\text { system }\end{array}$ \\
\hline 1 & Pure Voltage signal & 100 & 100 & 100 \\
\hline 2 & Voltage Sag & 100 & 100 & 100 \\
\hline 3 & Voltage Swell & 100 & 100 & 98 \\
\hline 4 & Voltage Surge & 100 & 98 & 98 \\
\hline 5 & Voltage interruption & 100 & 99 & 100 \\
\hline 6 & Harmonics & 100 & 99 & 98 \\
\hline 7 & $\begin{array}{l}\text { Sag } \\
\text { Harmonics }\end{array}$ & 100 & 100 & 100 \\
\hline 8 & $\begin{array}{l}\text { Swell with } \\
\text { Harmonics }\end{array}$ & 100 & 100 & 99 \\
\hline 9 & Flicker & 100 & 98 & 99 \\
\hline 10 & Notch & & 99.22 & 99.0 \\
\hline & Overall accuracy & & & \\
\hline
\end{tabular}

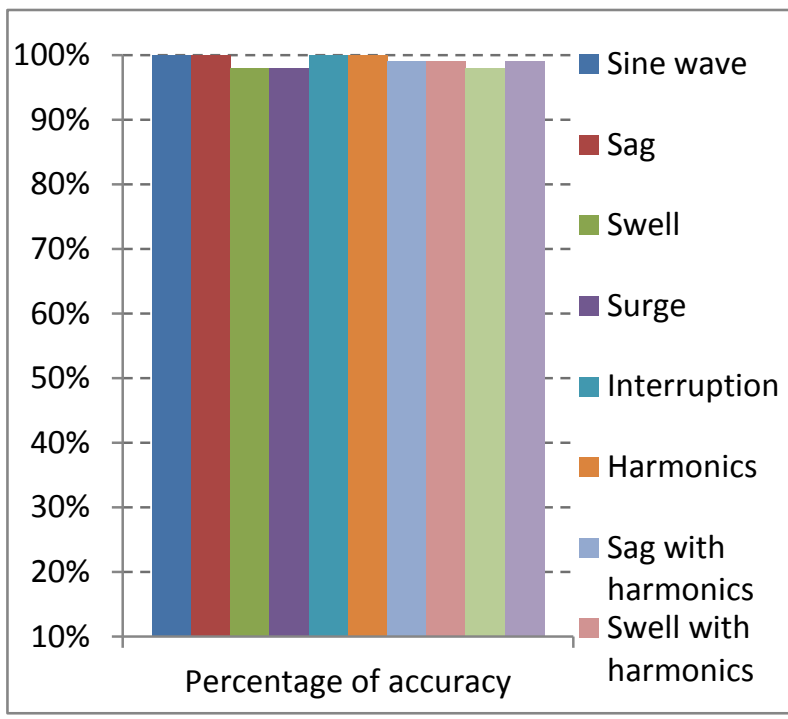

Figure 16.Bar diagram for the percentage of accuracy of the proposed method

\section{CONCLUSION}

This paper demonstrates a new approach for diagnosis and classification of various power quality disturbances using Hilbert transform and fuzzy classifier. The power disturbance waveforms were generated using Matlab simulink on test system and then processed through the Hilbert transform. The input features such as standard deviation and variances were extracted by Hilbert transform. The fuzzy expert system has been applied for classifying the various power quality disturbances. This novel method enables the accurate classification of all nine types of power quality disturbances 
and their simulation results demonstrate the performance of the Hilbert transform technique. The classification accuracy has been validated by comparing their results obtained by the proposed technique against Hilbert transform based neural classifier. Through there is a marginal/slight reduction in the overall value of classification accuracy, proposed method still proves to be an efficient one from the point of view of computational effort.

\section{REFERENCES}

[1] Shyh-Jier Huang, Cheng-Tao Hsieh and Ching-Lien Huang, "Application of wavelets to classify power system disturbances", Electric power systems research, 1998 .

[2] G.T.Heydt, P.S.Fjeld, C.C.Liu, D.Pierce, L.Tu,G.Hensley, "Applications of the windowed FFT to Electric Power quality assessment", IEEE Transaction on power delivery, October 1999.

[3] A.M. Gaouda, M.R.Sultan, A.Y.Chinkani and M.M.A. Salama, "Power quality detection and classification using wavelet-multiresolution signal decomposition" IEEE Transaction on power delivery, Vol 14, no.4, October 1999.

[4] A.M. Gaouda, S.H. Kanoun, M.M.A. Salama, "On-line disturbance classification using nearest neighbor rule", Electric power systems research, 2001.

[5] A.Elmitwally, S.Farghal, M.Kandil, S.Abdelkader, and M.Elkateb, "Proposed wavelet-neuro fuzzy combined system for power quality violations detection and diagnosis", IEEE Transaction, 2001.

[6] Min Wang, Piotr Ochenkowski, and Alexander Mamishev, "Classification of power quality disturbances using time-frequency ambiguity plane and neural networks", IEEE Transaction, 2001.

[7] Francisco Jurado , Jose' R. Saenz, "Comparison between discrete STFT and wavelets for the analysis of power quality events", Electric power systems research, 2002.

[8] P.K. Dash, B.K. Panigrahi, G. Panda, "Power quality analysis using S-transform", IEEE Transaction on power delivery, Vol 18, no.2, April 2003.

[9] P.K Dash, I. W. C. Lee, "S-transform-based intelligent system for classification of power quality disturbance signals", IEEE Transaction on industrial electronics, Vol 50, no.4, August 2003.

[10] P.K. Dash, B.K. Panigrahi, G. Panda, and D.K.Sahoo, "Power quality disturbance data compression, detection and classification using integrated spline wavelet and Stransform", IEEE Transaction on power delivery, Vol 18, no.2, April 2003.

[11] M. V. Chilukuri and P. K. Dash, "Multi resolution Stransform-based fuzzy recognition system for power quality events", IEEE Transaction on power delivery, Vol 19, no.1, January 2004.

[12] Dogan gokhan ece, and Omer nezih gerek, "Power quality event detection using joint 2-D-wavelet subspaces", IEEE Transaction on instrumentation and measurement, Vol 53, no.4, August 2004

[13] A. K. Pradhan, A. Routray, A. Behera, "Power quality disturbance classification employing modular wavelet network", IEEE Transactions, 2006

[14] Haibo He, Janusz A.Starzyk, A self organizing learning array system for power quality classification based on wavelet transform , IEEE Transaction on power delivery, Vol 21, no.1, January 2006.

[15] Peter G. V. Axelberg, Irene Yu-Hua Gu and Math H. J. Bollen, "Support vector machine for classification of voltage disturbances", IEEE Transactions on power delivery, July 2007.

[16] S. Mishra, C. N. Bhende, and B. K. Panigrahi, "Detection and Classification of Power Quality Disturbances Using S-Transform and Probabilistic Neural Network", IEEE Trans. Power Delivery. Vol.23, 2008.

[17] Chun-Yao Lee, Yi-Xing Shen, "Optimal Feature Selection for Power-Quality Disturbances Classification", IEEE Transaction on power delivery, oct 2011.

[18] Abdelazeem A.Abdelsalam, Azza A.Eldesouky, Abdelhay A.Sallam, "Characterization of power quality disturbance using hybrid technique of linear kalman filter and fuzzy expert system, Electric power systems research,2012.

[19] B. Biswal, M. Biswal, S. Mishra and R. Jalaja, "Automatic Classification of Power Quality Events Using Balanced Neural Tree", IEEE Transaction on Industrial electronics. Vol 61, January 2014.

[20] M.Sabarimalai manikandan, R.Samantary, Innocent Kamwa, Jan 2015 "Detection and classification of Power quality disturbances using sparse signal decomposition on hybrid dictionaries", IEEE Transactions on Instrument and measurement, Vol 64, No.1, Jan 2015. 